\title{
100-Gbps RZ Data Reception in 67-GHz Si-Contacted Germanium Waveguide p-i-n Photodetectors
}

Chen, Hongtao; Galili, Michael; Verheyen, P.; De Heyn, P.; Lepage, G.; De Coster, J.; Balakrishnan, S.; Absil, P.; Oxenløwe, Leif Katsuo; Van Campenhout, J.

Total number of authors:

11

Published in:

Journal of Lightwave Technology

Link to article, DOI:

10.1109/JLT.2016.2593942

Publication date:

2017

Document Version

Peer reviewed version

Link back to DTU Orbit

Citation (APA):

Chen, H., Galili, M., Verheyen, P., De Heyn, P., Lepage, G., De Coster, J., Balakrishnan, S., Absil, P.

Oxenløwe, L. K., Van Campenhout, J., \& Roelkens, G. (2017). 100-Gbps RZ Data Reception in 67-GHz Si-

Contacted Germanium Waveguide p-i-n Photodetectors. Journal of Lightwave Technology, 35(4), 722-726.

https://doi.org/10.1109/JLT.2016.2593942

\section{General rights}

Copyright and moral rights for the publications made accessible in the public portal are retained by the authors and/or other copyright owners and it is a condition of accessing publications that users recognise and abide by the legal requirements associated with these rights.

- Users may download and print one copy of any publication from the public portal for the purpose of private study or research.

- You may not further distribute the material or use it for any profit-making activity or commercial gain

- You may freely distribute the URL identifying the publication in the public portal 


\title{
100-Gbps RZ Data Reception in $67-\mathrm{GHz}$ Si-Contacted Germanium Waveguide p-i-n Photodetectors
}

\author{
Hongtao Chen, M. Galili, P. Verheyen, P. De Heyn, G. Lepage, J. De Coster, S. Balakrishnan, P. Absil, L. Oxenlowe, \\ J. Van Campenhout, and G. Roelkens
}

(Top Scored)

\begin{abstract}
Abltbac $>$ We demonstrate 100-Gbps silicon-contacted germanium waveguide $p$-i-n photodetectors integrated on imec's silicon photonics platform. The performance of 14 and $20 \mu \mathrm{m}$ long devices is compared. The responsivity of the devices is 0.74 and $0.92 \mathrm{~A} / \mathrm{W}$ at $1550 \mathrm{~nm}$, respectively.
\end{abstract}

Index Terms-Germanium, integrated optoelectronics, optical communications, photodetectors.

\section{INTRODUCTION}

A DVANCED optical receivers require photodetectors with high opto-electrical bandwidth, high responsivity and low dark current. Germanium waveguide p-i-n photodetectors have been studied extensively for this purpose as they can be realized on silicon photonic integrated circuits [1]-[13]. Conventional Ge $\mathrm{p}-\mathrm{i}-\mathrm{n}$ photodetectors require a metal contact on $\mathrm{Ge}$ to form the $\mathrm{p}-\mathrm{i}-\mathrm{n}$ junction. As the process to form a metal contact to $\mathrm{Ge}$ is less well developed, the high contact resistance at the metal/Ge interface [14] contributes to a large RC-constant, which normally determines the opto-electrical bandwidth of the Ge p-i-n photodetector. This limits the performance of Ge $\mathrm{p}-\mathrm{i}-\mathrm{n}$ photodetectors in high-speed optical communication systems. $100 \mathrm{Gbps}$ data reception using Ge photodetectors has therefore not been demonstrated before.

We demonstrated a Ge p-i-n photodetector without metal contacts on $\mathrm{Ge}$, grown on and contacted through a silicon $\mathrm{p}-\mathrm{i}-\mathrm{n}$ diode structure, adopting a $400 \mathrm{~nm}$ thick Ge layer (referred to as Si-LPIN GePD hereafter) [11]. The opto-electrical 3-dB

Manuscript received June 1, 2016; revised July 15, 2016; accepted July 20, 2016. Date of publication July 21, 2016; date of current version February 22, 2017.

H. Chen and G. Roelkens are with the Photonics Research Group, Department of Information Technology, Ghent University-imec, Ghent B-9000, Belgium (e-mail: Hongtao.Chen@imec.be; gunther.roelkens@intec.ugent.be).

M. Galili and L. Oxenlowe are with the DTU Fotonik, Technical University of Denmark, Kongens Lyngby 2800, Denmark (e-mail: mgal@fotonik. dtu.dk; 1kox@fotonik.dtu.dk).

P. Verheyen, P. De Heyn, G. Lepage, J. De Coster, S. Balakrishnan, P. Absil, and J. Van Campenhout are with the Interuniversity Microelectronics Center, Leuven B-3000, Belgium (e-mail: peter.verheyen@imec.be; Peter.DeHeyn@ imec.be; guy.lepage@imec.be; Jeroen.DeCoster@imec.be; Sadhishkumar. Balakrishnan@imec.be; philippe.absil@imec.be; joris.vancampenhout@ imec.be).

Color versions of one or more of the figures in this paper are available online at http://ieeexplore.ieee.org.

Digital Object Identifier 10.1109/JLT.2016.2593942

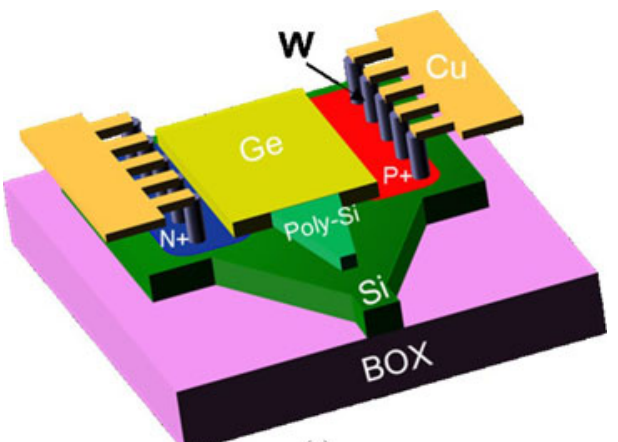

(a)

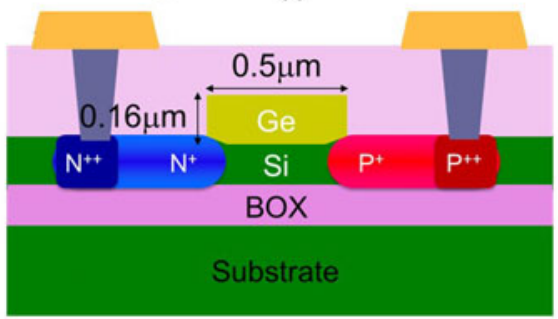

(b)

Fig. 1. (a) 3-D schematic of the Si-LPIN GePD. The poly-Si taper is $120 \mathrm{~nm}$ thick, with a width varying from $150 \mathrm{~nm}$ to $250 \mathrm{~nm}$ over a length of $20 \mu \mathrm{m}$, and the single-mode $\mathrm{Si}$ waveguide is $450 \mathrm{~nm}$ wide. (b) Cross-section schematic of the Si-LPIN GePD with a $0.16 \mu \mathrm{m}$ thick and $0.5 \mu \mathrm{m}$ wide Ge layer.

bandwidth was transit-time limited to $20 \mathrm{GHz}$ at $-1 \mathrm{~V}$ bias at $1550 \mathrm{~nm}$. Removing the metal contacts on Ge significantly enhances the responsivity as light absorption from the metal contacts is responsible for a substantial responsivity loss. The measured responsivity at $-1.2 \mathrm{~V}$ bias was over $1 \mathrm{~A} / \mathrm{W}$ across the whole C-band. In addition, the device showed a very low dark current of $3 \mathrm{nA}$ at $-1 \mathrm{~V}$.

In [15], [16] we demonstrated that by adopting a $160 \mathrm{~nm}$ thick Ge layer to reduce the transit time, the opto-electrical 3- $\mathrm{dB}$ bandwidth at $-1 \mathrm{~V}$ bias was enhanced to $67 \mathrm{GHz}$ at $1550 \mathrm{~nm}$ for a $14 \mu \mathrm{m}$ long Si-LPIN GePD. The junction capacitance was $6.8 \mathrm{fF}$ at $-1 \mathrm{~V}$. Light coupling from the silicon-oninsulator (SOI) waveguide to the Ge waveguide was optimized by adding a poly-Si taper on top of the fully etched Si taper as shown in Fig. 1(a). The measured responsivity at $-1 \mathrm{~V}$ bias was $0.74 \mathrm{~A} / \mathrm{W}$ at $1550 \mathrm{~nm}$. The dark current was as low as $4 \mathrm{nA}$ at 


\section{Doping distribution $\left(\mathrm{cm}^{-3}\right)$}
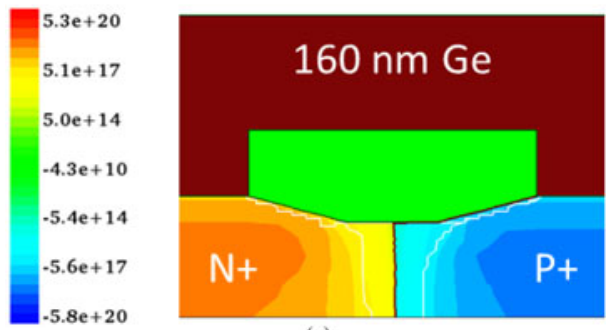

(a)

Electric field $(\mathrm{V} / \mathrm{cm})$
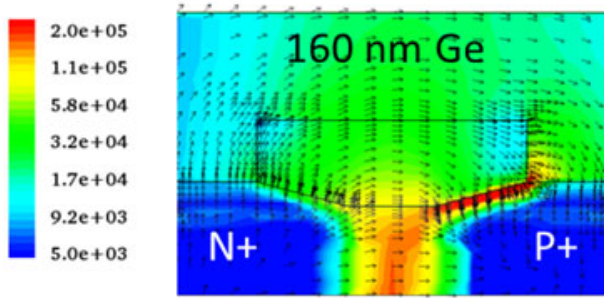

(b)

Fig. 2. (a) Simulated doping distribution in the Si-LPIN GePD using Sentaurus Process. (b) Simulated electric field distribution in the Si-LPIN GePD at $-1 \mathrm{~V}$ bias using Sentaurus Device. The electric field direction is annotated in the graph.

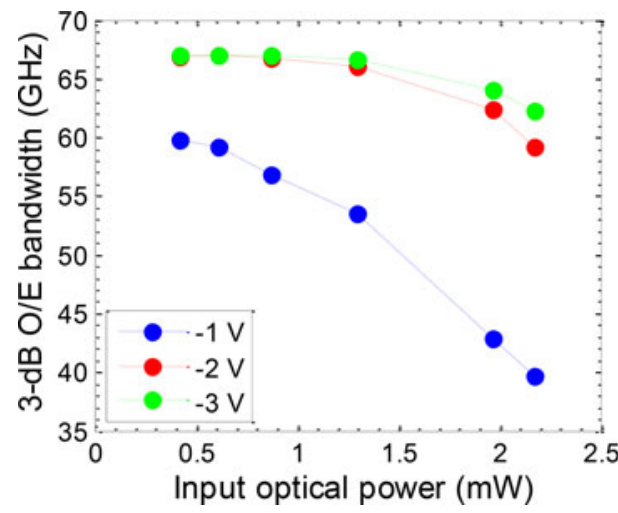

Fig. 3. 3-dB opto-electrical bandwidth as a function of input optical power at $1550 \mathrm{~nm}$ wavelength for the $14 \mu \mathrm{m}$ long Si-LPIN GePD (reproduced with permission from [16])

-1 V. 56 Gbps on-off keying non-return-to-zero data reception was demonstrated with clear open eye diagrams at $1550 \mathrm{~nm}$ at $-1 \mathrm{~V}$ bias [16].

In this paper, $80 \mathrm{Gbps}$ and $100 \mathrm{Gbps}$ OOK data reception using the $14 \mu \mathrm{m}$ long Si-LPIN GePD are characterized, and clear open eye diagrams at $1550 \mathrm{~nm}$ wavelength are demonstrated using $80 \mathrm{Gbps}$ and $100 \mathrm{Gbps}$ on-off keying return-to-zero pseudo-random-bit-sequence data patterns generated using an optical time division multiplexing scheme [17], [18]. As the $14 \mu \mathrm{m}$ long Si-LPIN GePD is still transit-time limited, the potential performance improvement in terms of responsivity using a $20 \mu \mathrm{m}$ long Si-LPIN GePD is evaluated. The responsivity is improved to $0.92 \mathrm{~A} / \mathrm{W}$ at $1550 \mathrm{~nm}$ for this $20 \mu \mathrm{m}$ long Si-LPIN $\mathrm{GePD}$, and similarly clear $80 \mathrm{Gbps}$ and $100 \mathrm{Gbps}$ open eye diagrams at $1550 \mathrm{~nm}$ wavelength are demonstrated.

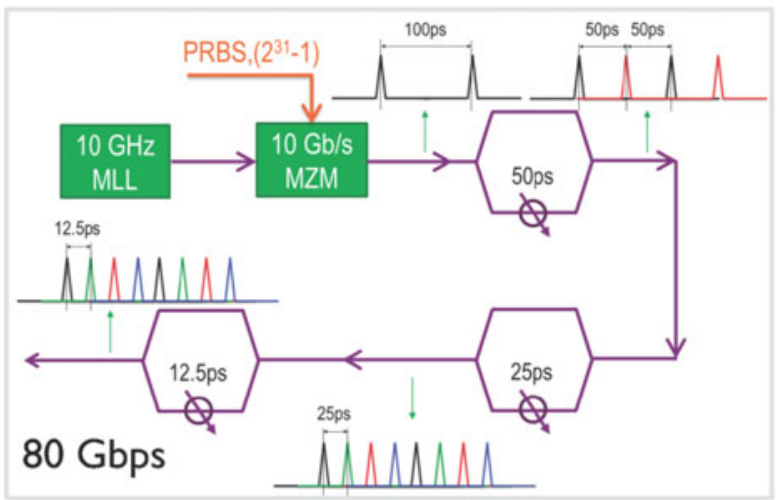

(a)

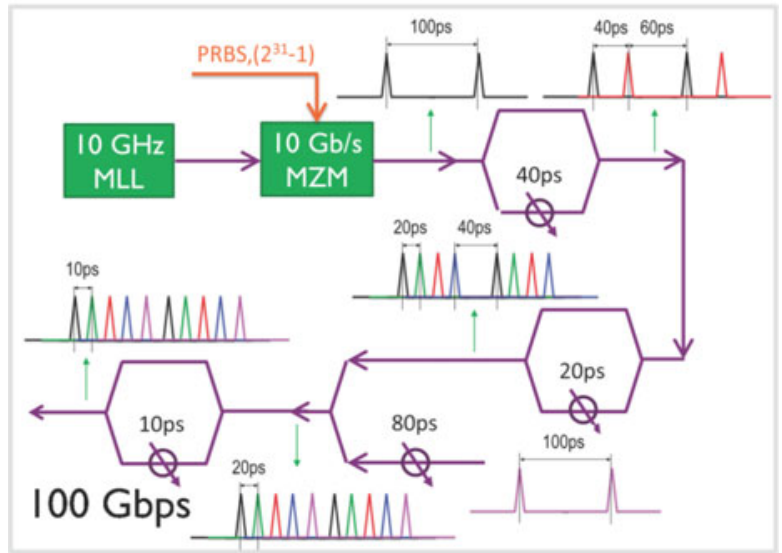

(b)

Fig. 4. Schematic diagrams illustrating the experimental set up generating the optical OOK RZ data streams at (a) $80 \mathrm{Gbps}$ and (b) $100 \mathrm{Gbps}$. MLL: mode-lock laser; MZM: Mach-Zehnder modulator.

\section{DEVICE DESIGN AND FABRICATION}

The Si-LPIN GePDs were fabricated in imec's fully integrated Si Photonics Platform along with Si modulators [19] and various passive devices [20]. They go through a process flow described in [21]. Light is coupled from a $220 \mathrm{~nm}$ thick singlemode $\mathrm{Si}$ waveguide ( $450 \mathrm{~nm}$ wide) to the Ge waveguide using a Si waveguide taper together with a $120 \mathrm{~nm}$ thick poly-Si taper (from $150 \mathrm{~nm}$ to $250 \mathrm{~nm}$ width over a length of $20 \mu \mathrm{m}$ ), as shown in Fig. 1(a). The Ge layer dimensions and doping configuration in the Si-LPIN GePD are shown in Fig. 1(b). The doping distribution in the Si-LPIN GePD is shown in Fig. 2(a), simulated using Sentaurus Process.

The electric field distribution in the Si-LPIN GePD at $-1 \mathrm{~V}$ bias obtained by numerically solving the Poisson's equation using Sentaurus Device is shown in Fig. 2(b). In the Ge region, the electric field is stronger than $10^{4} \mathrm{~V} / \mathrm{cm}$ at $-1 \mathrm{~V}$, strong enough for photo-generated carriers to drift at their saturation velocity. Therefore, the opto-electrical bandwidth limitation by transit time is minimized. The $14 \mu \mathrm{m}$ long Si-LPIN GePD exhibits a 3-dB O/E bandwidth of $60 \mathrm{GHz}$ and above (i.e. the RF power delivered by the photodetector to a $50 \Omega$ load drops by a factor of 2 at $60 \mathrm{GHz}$ and above) at $1550 \mathrm{~nm}$ as seen in Fig. 3 (reproduced from [16]). Such a high bandwidth should allow $100 \mathrm{Gbps}$ on-off keying data reception as will be discussed in the subsequent sections. 


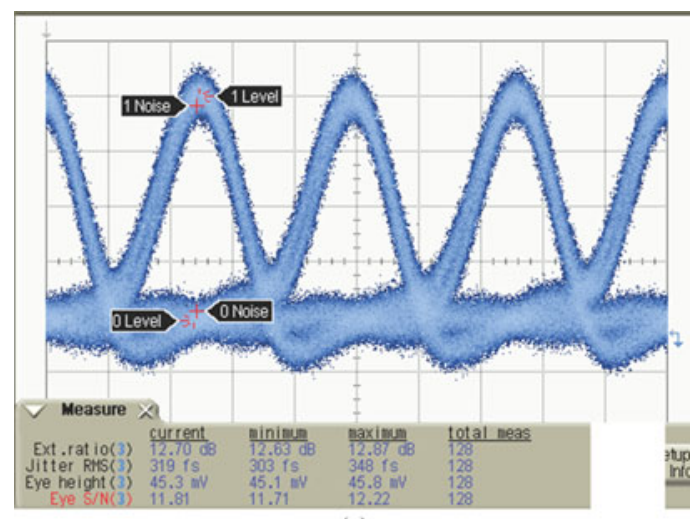

(a)

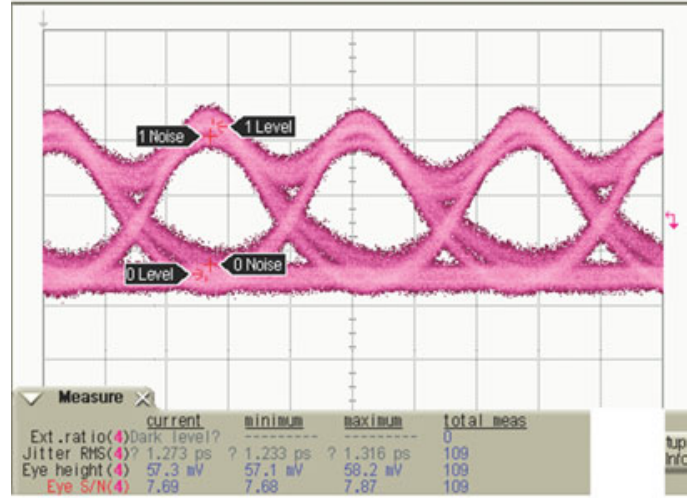

(b)

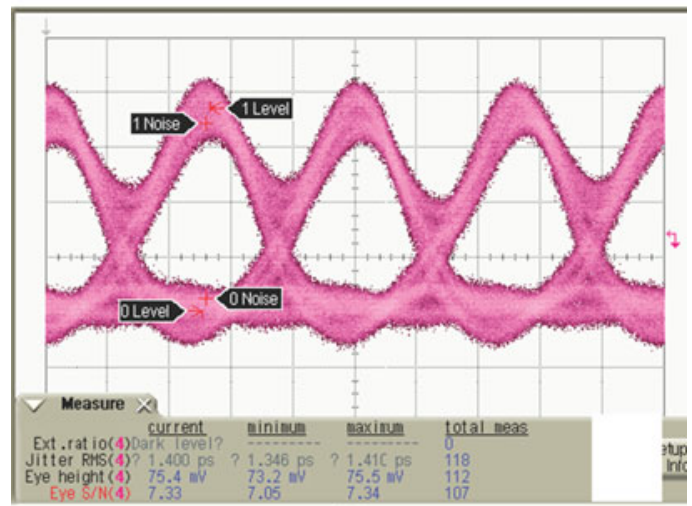

(c)

Fig. 5. The 80 Gbps RZ eye diagram measured using (a) a $70 \mathrm{GHz}$ commercial p-i-n photodetector (u2t XPDV 3120R), (b) the $14 \mu \mathrm{m} \mathrm{Si-LPIN} \mathrm{GePD} \mathrm{at}-1 \mathrm{~V}$ bias. (c) the $14 \mu \mathrm{m}$ Si-LPIN GePD at $-2 \mathrm{~V}$ bias. X scale: $5.0 \mathrm{ps} / \mathrm{div}$, Y scale: $34.8 \mathrm{mV} /$ div. These X\&Y scales are for the eyes measured on the Si-LPIN GePD.

\section{80 GBPS AND 100 GBPS DATA RECEPTION USING A $14 \mu \mathrm{M}$ LONG SI-LPIN GEPD}

The data reception performance of the $14 \mu \mathrm{m} \mathrm{Si-LPIN} \mathrm{GePD}$ was characterized at $1550 \mathrm{~nm}$ wavelength using an on-off keying (OOK) return-to-zero (RZ) pseudo-random-bit-sequence (PRBS) data pattern at $80 \mathrm{Gbps}$ and $100 \mathrm{Gbps}$, respectively. Schematic diagrams illustrating the experimental setup generating the optical OOK RZ data stream at $80 \mathrm{Gbps}$ and $100 \mathrm{Gbps}$ are shown in Fig. 4(a) and (b). Optical pulses from a $10 \mathrm{GHz}$ mode-locked laser (MLL) are on-off keying (OOK) modulated by a commercial Mach-Zehnder modulator at $10 \mathrm{Gbps}$. The modulated pulses are temporally multiplexed 3 times with de-

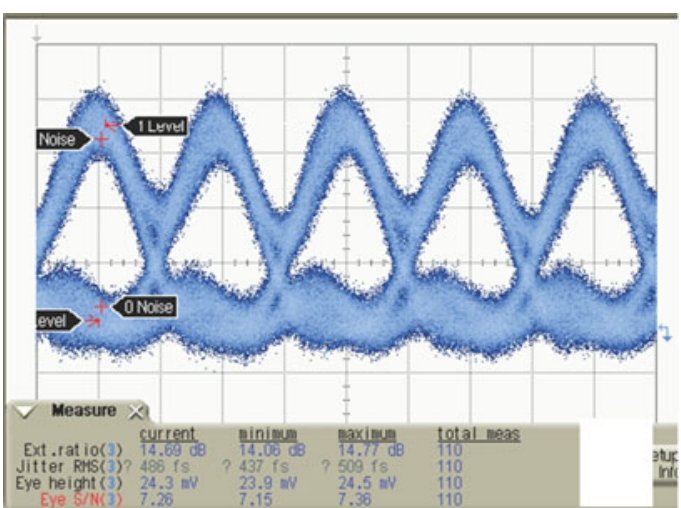

(a)

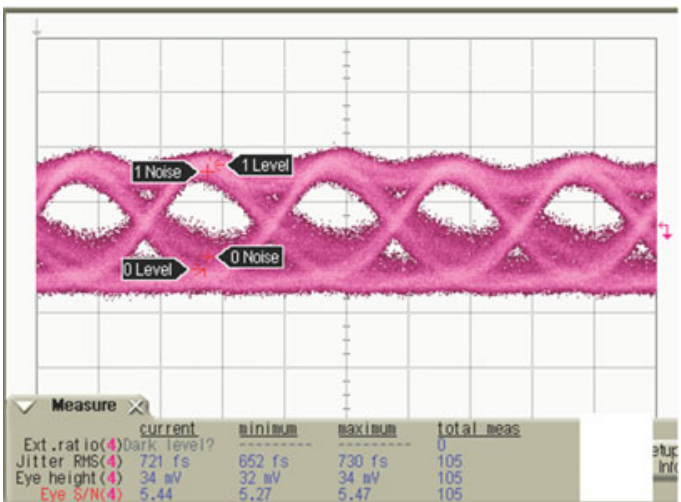

(b)

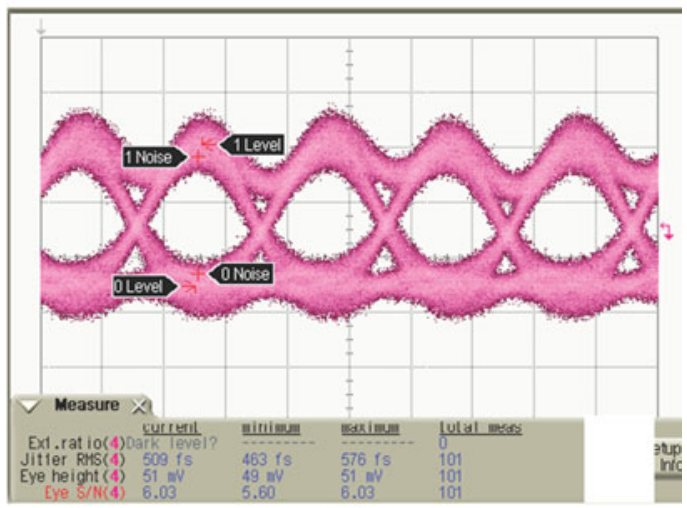

(c)

Fig. 6. The $100 \mathrm{Gbps} \mathrm{RZ}$ eye diagram measured using (a) a $70 \mathrm{GHz}$ commercial p-i-n photodetector (u2t XPDV 3120R), (b) the $14 \mu \mathrm{m}$ Si-LPIN GePD at $-1 \mathrm{~V}$ bias. (c) the $14 \mu \mathrm{m}$ Si-LPIN GePD at $-2 \mathrm{~V}$ bias. X scale: $5.0 \mathrm{ps} / \mathrm{div}$, Y scale: $39.4 \mathrm{mV} /$ div. These $\mathrm{X} \& \mathrm{Y}$ scales are for the eyes measured on the Si-LPIN GePD.

lays of $50 \mathrm{ps}, 25 \mathrm{ps}$ and $12.5 \mathrm{ps}$ to generate the $80 \mathrm{Gbps}$ data stream. For the $100 \mathrm{Gbps}$ data stream generation, the modulated pulses are firstly multiplexed 2 times with delays of $40 \mathrm{ps}$ and 20 ps. The generated optical pulses are then multiplexed with the original $10 \mathrm{Gbps}$ optical pulses with an 80-ps delay forming a 50 Gbps OOK signal. This is finally multiplexed with a 10-ps delay to create the targeted data rate of $100 \mathrm{Gbps}$. The OTDM data stream is injected in the silicon waveguide using a C-band fiber-to-chip grating coupler (insertion loss of $2.5 \mathrm{~dB}$ ). A bias voltage was applied to the Si-LPIN GePD using a $67 \mathrm{GHz}$ Picoprobe RF probe with a $50 \Omega$ termination connected to a $65 \mathrm{GHz}$ SHF bias-tee. The electrical output is measured with 


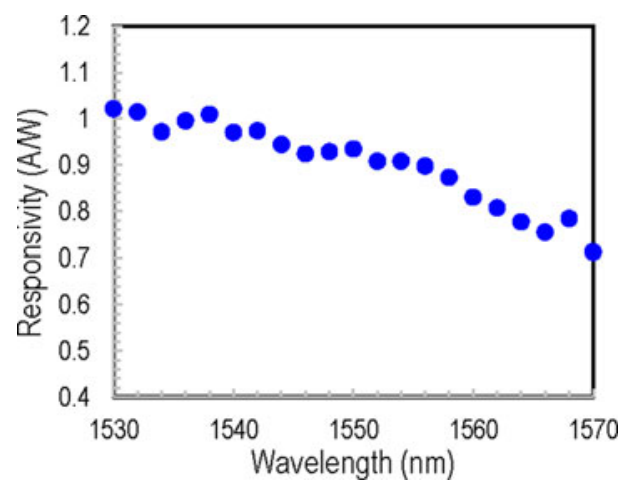

Fig. 7. Responsivity as a function of wavelength for the $20 \mu \mathrm{m}$ Si-LPIN GePD in the $\mathrm{C}$-band at $-1 \mathrm{~V}$ bias.

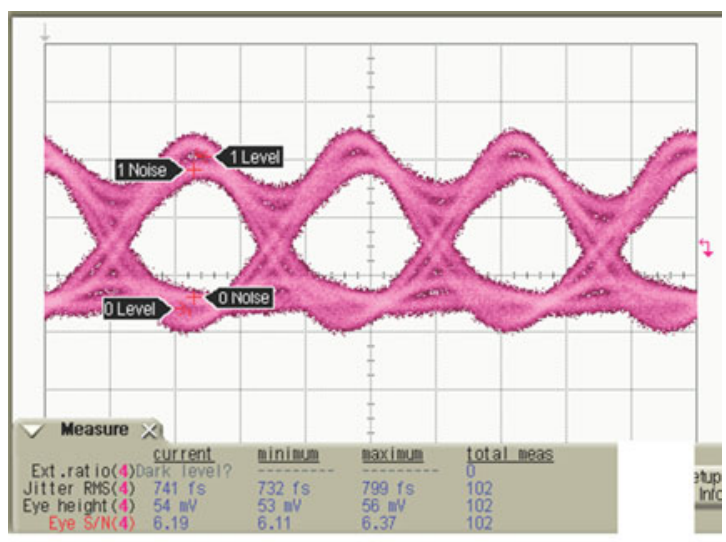

(a)

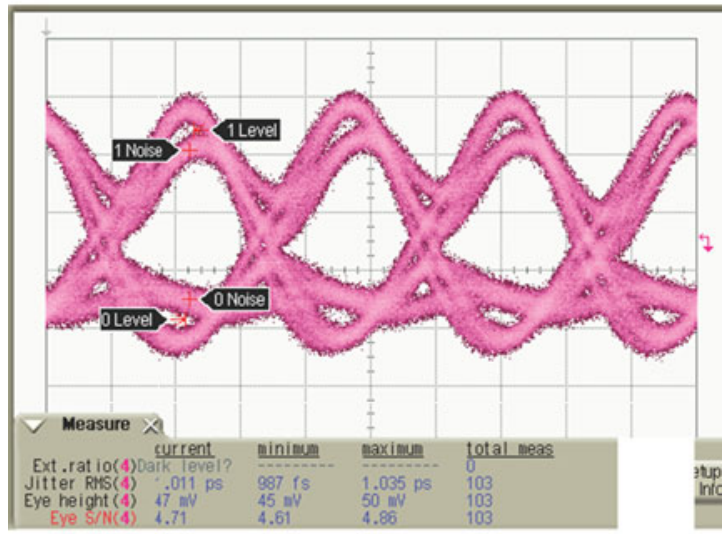

(b)

Fig. 8. The 80 Gbps RZ eye diagram measured using (a) the $20 \mu \mathrm{m}$ Si-LPIN GePD at $-1 \mathrm{~V}$ bias. (b) the $20 \mu \mathrm{m}$ Si-LPIN GePD at $-2 \mathrm{~V}$ bias. $\mathrm{X}$ scale: $5.0 \mathrm{ps} / \mathrm{div}$, Y scale: $39.4 \mathrm{mV} / \mathrm{div}$.

an Agilent Infiniium sampling oscilloscope with a $70 \mathrm{GHz}$ remote sampling head plug-in. Given the $50 \Omega$ termination on the probe, the effective responsivity of the photodiode seen by the scope is half of the reported DC responsivity due to the termination resistor being in parallel with the $50 \Omega$ input impedance of the scope.

The reference eye diagram of the 80 Gbps PRBS data pattern measured using a $70 \mathrm{GHz}$ commercial $\mathrm{p}$-i-n photodetector $(u 2 t X P D V-3120 R)$ is shown in Fig. 5(a). The extinction ratio of the transmitted data stream is $12.7 \mathrm{~dB}$. The electrical eye diagrams from the Si-LPIN GePD at $-1 \mathrm{~V}$ and $-2 \mathrm{~V}$ are shown

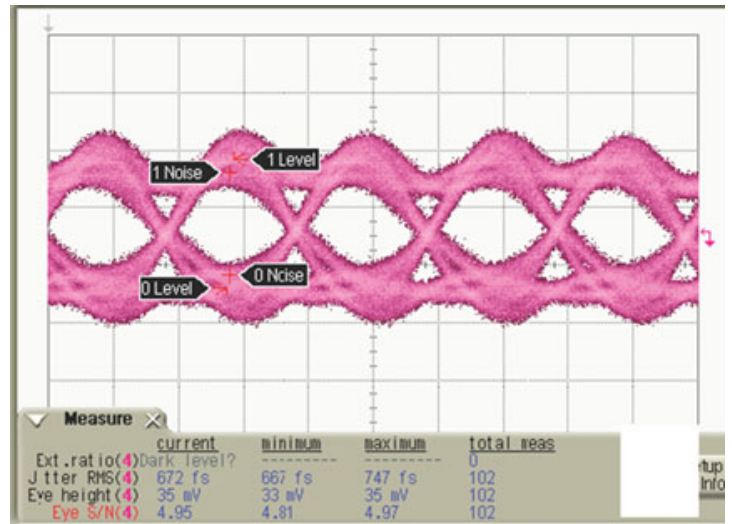

(a)

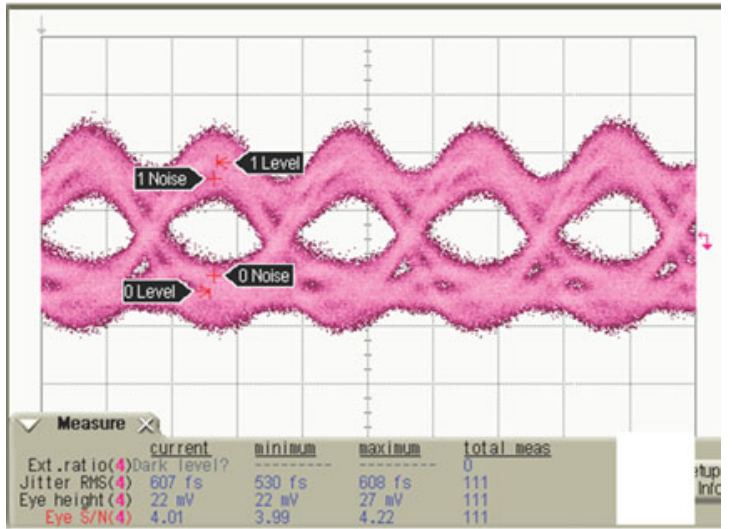

(b)

Fig. 9. The 100 Gbps $\mathrm{RZ}$ eye diagram measured using (a) the $20 \mu \mathrm{m}$ Si-LPIN GePD at $-1 \mathrm{~V}$ bias. (b) the $20 \mu \mathrm{m} \mathrm{Si-LPIN} \mathrm{GePD}$ at $-2 \mathrm{~V}$ bias. X scale: $5.0 \mathrm{ps} /$ div, Y scale: $39.4 \mathrm{mV} /$ div.

in Fig. 5(b) and (c), respectively. Fig. 6(a-c) show the eye diagrams measured in the 100 Gbps data reception experiment. The extinction ratio of the transmitted data stream is $14.6 \mathrm{~dB}$ in this case. The average waveguide-coupled optical power used in both the $80 \mathrm{Gbps}$ and $100 \mathrm{Gbps}$ experiment is $0.62 \mathrm{~mW}$. The corresponding 3-dB O/E bandwidth of the Si-LPIN GePD is $\sim 59 \mathrm{GHz}$ at $-1 \mathrm{~V}$ as seen in Fig. 3. This explains the bandwidth limitation at $-1 \mathrm{~V}$ bias especially in the $100 \mathrm{Gbps}$ eye diagram. This bandwidth limitation is overcome by biasing the device at $-2 \mathrm{~V}$, where the $14 \mu \mathrm{m} \mathrm{Si-LPIN} \mathrm{GePD}$ exhibits a 3-dB O/E bandwidth beyond $67 \mathrm{GHz}$. It should be mentioned that the eye diagrams of the Si-LPIN GePD are still worse than that of the commercial photodetector, especially at $100 \mathrm{Gbps}$. As there is a $67 \mathrm{GHz}$ Picoprobe RF probe with a 50-ohm termination, a $65 \mathrm{GHz}$ SHF bias-tee, a $67 \mathrm{GHz}$ RF coaxial-cable and an Agilent Infiniium sampling oscilloscope with a $70 \mathrm{GHz}$ remote sampling head plug-in in the RF link in these on-chip largesignal data reception experiments, it is the frequency response of this RF link that is responsible for the reduced eye diagram quality.

\section{80 GBPS AND 100 GBPS DATA RECEPTION USING A $20 \mu \mathrm{M}$ LONG SI-LPIN GEPD}

The conclusion that the opto-electrical bandwidth of the $14 \mu \mathrm{m}$ long Si-LPIN GePD is limited by the transit-time and that the responsivity in the C-band $(0.74 \mathrm{~A} / \mathrm{W}$ at $1550 \mathrm{~nm})$ is 
partly limited by the short device length was drawn in [16]. This indicates that the responsivity of the $14 \mu \mathrm{m} \mathrm{Si-LPIN} \mathrm{GePD}$ in the C-band can be improved by increasing the length of the device without compromising on the opto-electrical bandwidth. Therefore, responsivity measurements and $80 \mathrm{Gbps} / 100 \mathrm{Gbps}$ data reception experiments were implemented for a $20 \mu \mathrm{m}$ long $\mathrm{Si}-\mathrm{LPIN} \mathrm{GePD}$. The responsivity as a function of wavelength in the C-band of a $20 \mu \mathrm{m}$ long Si-LPIN GePD is shown in Fig. 7. The responsivity at $1550 \mathrm{~nm}$ is improved to $0.92 \mathrm{~A} / \mathrm{W}$ benefiting from this $6 \mu \mathrm{m}$ device length scaling.

The 80 Gbps and 100 Gbps RZ PRBS data reception experiments at $1550 \mathrm{~nm}$ were also implemented for the $20 \mu \mathrm{m}$ long Si-LPIN GePD. Figs. 8 and 9 show the electrical eye diagrams from the $20 \mu \mathrm{m} \mathrm{Si-LPIN} \mathrm{GePD}$ at $80 \mathrm{Gbps}$ and $100 \mathrm{Gbps}$, respectively. The optical data patterns used in these experiments are the same as those used in the experiments on the $14 \mu \mathrm{m}$ Si-LPIN GePD. The average waveguide-coupled input optical power used in both the $80 \mathrm{Gbps}$ and $100 \mathrm{Gbps}$ experiment is $0.51 \mathrm{~mW}$ in this case. Clear open eye diagrams are again obtained at both data rates. Compared to the $14 \mu \mathrm{m}$ device, the eye diagrams of the $20 \mu \mathrm{m}$ device show a slightly slower response, indicating a small reduction of the device bandwidth by scaling the device length to $20 \mu \mathrm{m}$. Also more jitter and overshoot can be observed.

\section{CONCLUSION}

$100 \mathrm{Gbps}$ Ge p-i-n photodetectors without metal contacts on Ge integrated on imec's silicon photonics platform was demonstrated. The high responsivity at $1550 \mathrm{~nm}$ of $0.74 \mathrm{~A} / \mathrm{W}$ and $0.92 \mathrm{~A} / \mathrm{W}$ for a $14 \mu \mathrm{m}$ and $20 \mu \mathrm{m}$ long device respectively and low dark current of $4 \mathrm{nA}$ at $-1 \mathrm{~V}$ bias make it an attractive component for high bitrate optical transceivers.

\section{ACKNOWLEDGMENT}

The authors would like to thank imec's mask preparation team and process line for their contributions. They would also like to thank M. Piels from DTU Fotonik for her useful discussions in the data reception experiments.

\section{REFERENCES}

[1] T. Yin et al., "31 GHz Ge n-i-p waveguide photodetectors on silicon oninsulator substrate," Opt. Exp., vol. 15, no. 21, pp. 13965-13971, 2007.

[2] L. Vivien et al., " $42 \mathrm{GHz}$ p.i.n Germanium photodetector integrated in a silicon-on-insulator waveguide," Opt. Exp., vol. 17, no. 8, pp. 6252-6257, 2009.

[3] D. Feng et al., "High-speed Ge photodetector monolithically integrated with large cross-section silicon-on-insulator waveguide," Appl. Phys. Lett., vol. 95 , no. 26 , p. 261105,2009

[4] S. Liao et al., " $36 \mathrm{GHz}$ submicron silicon waveguide germanium photodetector," Opt. Exp., vol. 19, no. 11, pp. 10967-10972, 2011.

[5] C. T. DeRose et al., "Ultra-compact $45 \mathrm{GHz}$ CMOS compatible Germanium waveguide photodiode with low dark current," Opt. Exp., vol. 19, no. 25, pp. 24897-24904, 2011.

[6] L. Vivien et al., "Zerobias $40 \mathrm{Gbit} / \mathrm{s}$ germanium waveguide photodetector on silicon," Opt. Exp., vol. 20, no. 2, pp. 1096-1101, 2012.

[7] G. Li et al., "Improving CMOS-compatible germanium photodetectors," Opt. Exp., vol. 20, no. 24, pp. 26345-26350, 2012.

[8] A. Novack et al., "Germanium photodetector with $60 \mathrm{GHz}$ bandwidth using inductive gain peaking," Opt. Exp., vol. 21, no. 23, pp. 28387-28393, 2013 .
[9] T.-Y. Liow, N. Duan, A. E.-J. Lim, X. Tu, M. Yu, and G.-Q. Lo, "Waveguide $\mathrm{Ge} / \mathrm{Si}$ avalanche photodetector with a unique low-heightprofile device structure," presented at the Opt. Fiber Commun. Conf., San Francisco, CA, USA, 2014, Paper M2G.6.

[10] Y. Zhang et al., "A high responsivity photodetector absent metalgermanium direct contact," Opt. Exp., vol. 22, no. 9, pp. 11367-11375, 2014

[11] H. Chen et al., "High responsivity low-voltage 28Gbps Ge p-i-n photodetector with silicon contacts," J. Lightw. Technol., vol. 33, no. 4, pp. 820-824, Nov. 2014

[12] R. Going, T. J. Seok, J. Loo, K. Hsu, and M. C. Wu "Germanium wraparound photodetectors on silicon photonics," Opt. Exp., vol. 23, no. 9, pp. 11975-11984, 2015.

[13] S. Lischke et al., "High bandwidth, high responsivity waveguide-coupled germanium p-i-n photodiode," Opt. Exp., vol. 23, no. 21, pp. 27213-27220, 2015 .

[14] B. Yang et al., "Low-contact-resistivity nickel germanide contacts on $\mathrm{n}+\mathrm{Ge}$ with phosphorus/antimony co-doping and Schottky barrier height lowering," in Proc. Int. Silicon-Germanium Technol. Device Meeting, 2012, vol. 1, pp. 1-2.

[15] H. Chen et al., "-1 V bias 56 Gbps germanium waveguide p-i-n Photodetector with silicon contacts," presented at the Opt. Fiber Commun. Conf., Anaheim, CA, USA, 2016, Paper Tu2D.6.

[16] H. Chen et al., "-1 V bias $67 \mathrm{GHz}$ bandwidth Si-contacted Ge p-i-n photodetector for optical links at $56 \mathrm{~Gb} / \mathrm{s}$ and beyond," Opt. Exp., vol. 24 , no. 5, pp. 4622-4631, 2016

[17] M. Galili et al., "650 Gbit/s OTDM transmission over $80 \mathrm{~km}$ SSMF incorporating clock recovery, channel identification and demultiplexing in a polarisation insensitive receiver," presented at the Opt. Fiber Commun. Conf., San Diego, CA, USA, 2010, Paper OWO3.

[18] H. Hu et al. "Synchronization, retiming and OTDM of an asynchronous 10 gigabit ethernet NRZ packet using a time lens for terabit ethernet," presented at the Eur. Conf. Opt. Commun., Geneva, Switzerland, 2011, Paper Tu.3.K.4.

[19] M. Pantouvaki et al., "20 Gbps silicon ring modulator co-integrated with a Ge monitor photodetector," presented at the Eur. Conf. Opt. Commun., London, U. K., 2013, Paper We.3.B.2.

[20] P. De Heyn et al. "Fabrication-tolerant four-channel wavelength-divisionmultiplexing filter based on collectively tuned Si microrings," J. Lightw. Technol., vol. 31, no. 16, pp. 2785-2792, Jul. 2013.

[21] P. Verheyen et al., "Highly uniform 25 Gbps Si photonics platform for high-density, low-power WDM optical interconnects," presented at the Integr. Photon. Res., Silicon Nanophoton. Conf., San Diego, CA, USA, 2014, Paper IW3A.4.

Hongtao Chen received the Master's degree in electronics and communication engineering from the Institute of Semiconductor, Chinese Academy of Sciences, Beijing, China, in 2012. He is currently working toward the Ph.D. degree in the Photonic Research Group, Ghent University, Ghent, Belgium.

He had been working on high-speed carrier-depletion Mach-Zehnder Si optical modulators. His research interest includes low-power Si photonics optical interconnects. He focused on developing advanced Germanium p-i-n photodetectors and avalanche photodetectors on the imec Si photonics platform, in close collaboration with imec, Belgium.

M. Galili, biography not available at the time of publication.

P. Verheyen, biography not available at the time of publication.

P. De Heyn, biography not available at the time of publication.

G. Lepage, biography not available at the time of publication.

J. De Coster, biography not available at the time of publication.

S. Balakrishnan, biography not available at the time of publication.

P. Absil, biography not available at the time of publication.

L. Oxenlowe, biography not available at the time of publication

J. Van Campenhout, biography not available at the time of publication.

G. Roelkens, biography not available at the time of publication. 